\title{
Simon ATELŠEK
}

\section{NAVAJANJE PREVZETIH JEZIKOSLOVNIH TERMINOV IN CELOVITOST POJMOVNIH SKUPIN V CIGALETOVI ZNANSTVENI TERMINOLOGIJI (1880)}

Coвiss: 1.01

HTTPS://DOI.ORG/10.3986/JZ.V25I1.7566

Ob 200. obletnici rojstva pravnika in jezikoslovca Mateja Cigaleta (1819-1889) v pričujočem prispevku predstavljamo prevzemanje na področju jezikoslovne terminologije in vzorčno analizo sedmih pojmovnih skupin s področja jezikoslovja v njegovi Znanstveni terminologiji (1880). Opozarjamo tudi na nekatere zanimivejše terminografske rešitve, ki smo jih opazili $\mathrm{v}$ analizi jezikoslovno označene terminologije $\mathrm{v}$ obravnavanem terminološkem slovarju.

Ključne besede: jezikoslovna terminologija, zgodovinsko jezikoslovje, prevzemanje, pojmovna skupina

\section{The Use of Borrowed Linguistic Terms and Comprehensiveness of Terminology Groups in Matej Cigale's Znanstvena terminologija (1880) \\ Coinciding with the two-hundredth anniversary of the birth of the Slovenian lawyer and linguist Matej Cigale (1819-1889), this article presents the borrowing of linguistic termi- nology and a sample analysis of seven linguistic terminology groups in his Znanstvena terminologija (Technical Terminology, 1880). Attention is also drawn to some interesting terminography solutions identified in the analysis of terminology labeled as linguistic in this dictionary. \\ Keywords: linguistic terminology, historical linguistics, borrowing, terminology group}

\section{UVOD}

Jezikoslovna terminologija, ki jo prinaša Znanstvena terminologija Mateja Cigaleta, je tule predstavljena $\mathrm{z}$ dveh vidikov. V prvem delu bomo skušali ugotoviti, iz katerih jezikov je avtor najpogosteje prevzemal jezikoslovno terminologijo in razloge za prevzemanje (poimenovalna vrzel, neustrezni termin), ter oceniti, $\mathrm{v}$ kolikšni meri lahko prevzemanje pripišemo Cigaletu, v kolikšni meri pa gre za termine, ki so bili že pred tem izpričani $v$ jezikoslovnih delih. V drugem delu pa bomo z vzorčno analizo sedmih pojmovnih skupin skušali ugotoviti, kako celovito je avtor predstavil področje jezikoslovja v svojem slovarju. 


\subsection{Gradivo}

Matej Cigale (1880: III-IV) v uvodu v obravnavani terminološki slovar s polnim naslovom Znanstvena terminologija s posebnim ozirom na srednja učilišča ${ }^{1}$ navaja, da mu je kot vzor služil hrvaški terminološki slovar, ki pa je nastal po zgledu češkega terminološkega slovarja. Češki terminološki slovar, ki ga je uredil Pavol Jozef Šafárik (po češko podpisan kot Pavel Josef Šafařík), je izšel leta 1853, in sicer z naslovom Německo-český slovník vědeckého názvoslovi pro gymnasia a reálné školy. Hrvaški terminološki slovar pa je izšel leta 1874 z naslovom Rječnik znanstvenoga nazivlja osobito za srednja učilišta pod uredništvom Bogoslava Šulka. ${ }^{2}$ Šlo je torej za širšo slovansko idejo o potrebi po večjezičnih terminoloških slovarjih predvsem za šolsko rabo. ${ }^{3}$

Ker Cigaletov slovar (podobno kot češki in hrvaški zgled) v skladu z usmeritvijo zajema več zelo različnih strokovnih področij, je bilo treba $v$ prvi fazi pričujoče raziskave poiskati oz. zamejiti jezikoslovne termine. Ker so termini v slovarju načeloma opremljeni s področnimi označevalniki, smo kot merilo za vključitev termina v analizo uporabili področni označevalnik gr. (grammatica 'slovnica'), ki ga Cigale med številnimi drugimi označevalniki navaja $v$ Tolmaču nekih kratic (IX). ${ }^{4} \mathrm{~V}$ celotnem slovarju smo našli okoli 220 iztočnic in podiztočnic,5 ki so

1 Gre za nemško-slovenski terminološki slovar, v katerem je Nemško-slovenski del (1-146) s Popravki in dostavki (147-148), ki mu sledi krajši Slovensko-nemški dodatek (149-171). Glede na seznam krajšav vsebuje termine s štiriindvajsetih različnih strokovnih področij. V nemško-slovenskem delu so med nemškimi iztočnicami navedene tudi posamezne latinske, Irena Orel (2005: 346) pa opozarja tudi na posamezne francoske iztočnice.

2 Primerjava vseh treh slovarjev je objavljena v Orel 2007, primerjava med češkim in slovenskim pa v Atelšek 2005.

3 Pri nas je na veliko potrebo po boljši skrbi za razvoj domače terminologije predvsem v luči šolske rabe opozoril Ivan Macun (1862: 67), ki je menil, da bi po zgledu Hrvatov morali tudi pri nas bolje organizirati domačo terminologijo in skrbeti za njen razvoj na vseh strokovnih področjih, ki so del šolskega programa.

$4 \quad$ Ob tem je treba opozoriti, da se zavedamo problematičnosti takšnega merila, saj na ta način $\mathrm{v}$ analizo nismo zajeli vseh jezikoslovnih terminov, ker jih avtor nekaj navaja tudi brez področnega označevalnika, npr. Homonym - raznoznačen, ali pa s kakšnim drugim področnim označevalnikom, npr. phil. (philosophia). Takšen primer je npr. termin Subject, phil.-podmet, subjekt, ki je v slovarju označen le kot termin s področja filozofije, medtem ko ga Cigale (1880: VIII) v uvodu v slovar omenja tudi kot jezikoslovni termin. - Po drugi strani pa na ta način v analizo nismo zajeli zgolj jezikoslovnih terminov, ker je Cigale z označevalnikom gr. opremil tudi nekaj takšnih, ki bi jih verjetno lahko uvrstili tudi na kakšno drugo strokovno področje oz. med splošno izrazje, npr. Bezeichnen, gr. stil. etc. - oznameniti, oznamenovati. Za bolj poglobljeno analizo jezikoslovne terminologije $\mathrm{v}$ obravnavanem delu bi bilo treba pregledati celoten slovar in si deloma na novo oblikovati merila za uvrstitev termina na področje jezikoslovja.

5 Cigale je pri oblikovanju slovarskih sestavkov uporabil metodo gnezdenja, kar pomeni, da lahko geselski sestavek vsebuje tudi korensko ujemalne podiztočnice (Orel 2007: 348). Podiztočnice so najpogosteje zloženke, pri katerih je prva sestavina iztočnična beseda; tako so npr. pri iztočnici Laut navedene podiztočnice Lautabstufung, Lautlehre, Lautrückung ... Poleg tega na ravni podiztočnice najdemo tudi glagole - v geslu Aussage je npr. navedena podiztočnica aussagen - in večbesedne termine, npr. v geslu Satz je navedena zveza zusammengesetzter Satz in pri iztočnici Wurzel podiztočnica wurzelhafter Consonant. V zvezi s predstavljenimi načeli 
opremljene s tem označevalnikom gr. (grammatica) in so skupaj z ustrezniki predstavljale gradivo za pričujočo analizo.

\section{O NAVAJANJU PREVZETIH JEZIKOSLOVNIH TERMINOV V ZNANSTVENI TERMINOLOGIJI}

\subsection{Cigaletova načela oblikovanja oz. popolnjevanja slovenske terminologije} Cigale se je dobro zavedal, da slovenščina na določenih strokovnih področjih nima dovolj razvite terminologije, zato je tej problematiki posvetil velik del uvoda $\mathrm{v}$ slovar. Kot eno izmed ustreznih sredstev za zapolnjevanje poimenovalnih vrzeli je izpostavil prevzemanje iz drugih slovanskih jezikov:

Dočim smo si Slovanje v oziru na telesna dela, zlasti v pastirstvu in poljedelstvu, - če stvar vzamemo v veliko, - do čuda blizu, moramo bližati a ne cepiti se tudi ondi, kjer še celino orjemo, v področji dušnega dela ali mišljenja. Ali bližanje tako obeta nekolikšen uspeh samo tedaj, če se mi, ki - po broju manji - ne moremo ni oblikovati se z onoliko zalogo dušnih sil, mi, ki smo vrhu tega nekoliko pozneje prijeli za delo, - primikamo številnejšim in v slovstvu naprednejšim bratom, namesto po nepotrebnem izkušati se $\mathrm{z}$ njimi. (Cigale 1880: VI)

Avtor se torej $\mathrm{v}$ uvodu zavzema za popolnjevanje slovenske terminologije na osnovi prevzemanja že uveljavljenih terminov iz drugih slovanskih jezikov, pri čemer zagovarja preoblikovanje oz. podomačevanje prevzetih terminov, da bodo bližji slovenskemu jezikovnemu sistemu. V zvezi s tem piše:

Razumè se pri tem samo ob sebi, da je izposojenke treba preukrajati po zahtevu slovenščine. (Cigale 1880: VII)

Takšna načelna usmeritev v prevzemanje je bila precej v skladu z duhom tedanjega časa, saj Martina Orožen (2003: 266) navaja, da je šlo v obdobju 1860-1885 za intenzivno arhaizacijo in slavizacijo slovenskega knjižnega jezika. Tudi na ravni terminologije so bile jasno izražene tovrstne težnje. Tako je npr. Ivan Macun (1862: 69) predlagal, da pri oblikovanju terminologije najprej poskušamo najti domačo besedo, če pa je nimamo, jo skušamo najti pri Hrvatih ali Srbih, ki so nam najbližji slovanski sosedje.

Glede na to, da Cigale v uvodu poleg hrvaškega omenja tudi češki vir oz. zgled, se zdi v obravnavanem slovarju poleg hrvaščine precej verjeten vir prevzemanja tudi češčina.

gnezdenja pa je treba opozoriti, da se v gradivu kažejo tudi posamezna odstopanja. Tako je npr. glagol Lautiren naveden kot samostojna iztočnica, čeprav bi lahko bil podiztočnica pri iztočnici Laut. Podobno sta kot samostojni iztočnici navedeni tudi besedni zvezi Steigendes Bindewort in Vergangene Zeit, ki bi prav tako glede na prej omenjena načela lahko bili podiztočnici. 


\subsection{Jezikoslovna terminologija in prevzemanje}

Pri jezikoslovni terminologiji je treba poudariti, da je bilo stanje verjetno bolj ugodno kot na drugih strokovnih področjih, tako da predpostavljamo, da je bilo potrebnega manj zapolnjevanja poimenovalnih praznin in posledično tudi manj prevzemanja iz drugih jezikov. Do tega obdobja je namreč nastalo že več slovnic slovenskega jezika, katerih metajezik $\mathbf{6}$ je bila slovenščina in ki jih je Cigale gotovo poznal. Vsaj za drugo izdajo slovenske slovnice Antona Janežiča je namreč znano, da je bil Cigale eden izmed pregledovalcev, ki so avtorju svetovali pri pripravi rokopisa in mu dajali pripombe nanj (Trojar 2017: 164). Predpostavljamo torej, da je Cigale vsaj jedro jezikoslovne terminologije lahko le popisal, prej predstavljena načela oblikovanja novih terminov oz. prevzemanja iz drugih slovanskih jezikov pa je uporabil zgolj v posameznih primerih, $\mathrm{v}$ katerih še ni bilo domačega termina, ali kadar je predlagal zamenjavo neustreznega izraza.

\subsection{Označevanje prevzete terminologije}

Cigale je prevzete termine v slovarju načeloma označeval, saj v Tolmaču nekih kratic (IX) navaja okrajšavi böhm. T. (böhmische Terminologie 'češka terminologija') in kroat. T. (kroatische Terminologie 'hrvaška terminologija'), ki označujeta že uvodoma omenjena slovarja, po katerih se je Cigale zgledoval, in okrajšavo za staro cerkveno slovanščino altsl. (altslovenisch). Oznak za druge tuje jezike na tem mestu (kot tudi ne drugje v uvodu) ne najdemo, čeprav so v slovarju izpričane še oznake za češčino (böhm.), hrvaščino (kroat.), hrvaščino/srbščino (kroatoserb.) in ruščino (russ.), ${ }^{7}$ ki jih je avtor sicer navajal na različne načine. Irena Orel (2005: 358) navaja, da so prevzete besede pogosto označene z zvezo nach dem/der/den 'po', npr. nach dem böhm. 'po češkem', in da so oznake za izvor lahko navedene pred izrazom ali v oklepaju za njim ali v oklepaju skupaj z izrazom. O označevanju prevzetega besedja je torej $\mathrm{v}$ uvodu malo podatkov, v slovarju pa lahko najdemo različne oznake, npr. altsl. in altslav., ter različne načine navajanja omenjenih oznak, npr. kroat. T. 'hrvaška terminologija' in nach der kroat. T. 'po hrvaški terminologiji', kar bi na osnovi pregledanega gradiva težko pripisali vsebinskim razlogom, temveč bolj kaže na terminografsko nedoslednost.8

V nadaljevanju bomo predstavili prevzeto jezikoslovno izrazje na ravni ustreznikov in tipe navajanja tovrstnega izrazja, pri čemer bomo ločeno predstavili izrazje, ki je glede na izvor neoznačeno, in v nadaljevanju izrazje, ki je glede na izvor označeno.

6 Kozma Ahačič (2015b: 17) navaja, da se je kontinuirano slovničarstvo v slovenskem metajeziku dejansko začelo leta 1847 , medtem ko so posamezna dela v slovenskem jeziku nastala že pred tem, npr. Zagajškova (1791) in Vodnikova slovnica (1811), ali pa so pretežno vsebovala tudi jezikoslovno terminologijo v slovenščini, npr. Pohlinova slovnica $(1768,1781)$.

7 Irena Orel (2005: 361) navaja še oznako za poljščino (poln.), ki pa na področju jezikoslovno označenega izrazja ni izpričana.

8 Gre zgolj za oceno, saj bi bilo za bolj dokončno sodbo o tem treba sistematično pregledati večji del slovarja. 


\subsubsection{Iztočnice in podiztočnice, ki imajo glede na izvor neoznačene ustreznike}

Pričakovano ima torej večina iztočnic in podiztočnic, označenih z gr., glede na izvor neoznačene ustreznike, in sicer je takšnih okoli 190. V tej skupini so torej na ravni ustreznikov navedeni v veliki meri domači termini, ki so bili v času nastanka slovarja že ustaljeni v stroki. Tako Cigale navaja posamezne jezikoslovne termine, ki so bili izpričani že v 16 . stoletju (npr. beseda, glas), ${ }^{9}$ še več pa je takšnih, ki so jih vpeljale slovnice slovenskega jezika v 19. stoletju, npr. besedno pleme Vodnikova slovnica (1811),10 samostavnik Janežičeva slovnica (1863).11 Poleg tega pa je treba opozoriti, da so glede na izvor neoznačeni tudi ustrezniki, ki so prevzeti iz klasičnih jezikov. Zanimivo je, da je bila v tem obdobju prisotna tudi ideja, da jezikoslovne terminologije za šolsko rabo sploh ne bi slovenili, temveč da bi uporabljali kar latinsko, ki bi jo kvečjemu podomačili v zapisu. Zagovornik takšne ideje je bil npr. Janez Šolar,12 ki jo utemeljuje z naslednjimi besedami:

Za šolo je po mojih mislih naj bolj treba gledati, da se terminologija slovenske slovnice od neslovenskih preveč ne odlikava, ker je za slovensko slovnico tako malo ur na teden odkazanih, da se lahko reče, da se učencom terminologija latinske ino gerške slovnice desetkrat terdneje v glavo vcepi kakor domača. (Šolar 1862: 204)

Mogoče lahko kot odmev takšnega pogleda na jezikoslovno terminologijo razumemo tudi latinske ustreznike, ki jih Cigale ponekod13 navaja ob iztočnicah in podiztočnicah s področja jezikoslovja. Sicer pa Cigale termine latinskega izvora pogosteje navaja $\mathrm{v}$ podomačenem zapisu, in sicer $\mathrm{v}$ nekaterih primerih kot edino poimenovalno možnost, drugod pa ob domačih ustreznikih. V obeh primerih ob tovrstnih prevzetih terminih ne navaja izvora.

Pri iztočnicah in podiztočnicah s področja jezikoslovja, ki imajo le glede na izvor neoznačene ustreznike, se kažejo trije tipi navajanja le-teh, in sicer:14

9 Prim. Ahačič 2007: 130-131.

10 Prim. Pacek 2003: 48.

11 Prim. Pacek 2003: 48.

12 Janez Šolar (1827-1882) je bil duhovnik, šolnik in jezikoslovec, ki si je prizadeval za slovenski učni jezik v šolah in za razvoj slovenskega jezika na osnovi stare cerkvene slovanščine in ostalih slovanskih jezikov. Medtem ko je nasprotoval prevzemanju iz nemščine, je na področju jezikoslovne terminologije iz praktičnih razlogov zagovarjal prevzemanje iz klasičnih jezikov. (Škofic 2006: 229-236)

13 Cigale navaja latinske ustreznike (navadno v oklepajih) npr. ob naslednjih iztočnicah in podiztočnicah: Haupt, Hauptzahlwörter - cardinalia; Hebung - arsis, ictus; Laut - sonus; Leid, Leideform - Passivum; Nebenabsicht, Nebenwort - adverbium; Procliticae - atona; Satz enunciatio, propositio; Satz, Satzband - copula; Silbe - syllaba; Verbal - verbalis; Vergangene Zeit - Perfectum; Verlängerung eines Wortes - paragoge; Wort, Wortreichthum - copia verborum; Zischlaute - sibilantes.

14 Ker je v slovarju na ravni iztočnic in podiztočnic 190 jezikoslovnih terminov $\mathrm{z}$ glede na izvor neoznačenimi ustrezniki, v pričujoči skupini navajamo le nekaj izbranih primerov. 
(a) Ob iztočnici ali podiztočnici je naveden le domači ustreznik:

Beiwort - pridevnik

Casus - padež

Conjunction - veznik

Declination - sklanjanje, sklanjatev (Š́́lar) 15

Form $>\mathbf{1 6}$ Formenlehre - oblikoslovje

Fürwort - zaimenica, zaimek

Laut - glas, glasek

Steigendes Bindewort $>$ Steigerung - stopnjevanje

Wort - beseda

Wort $>$ Wortarten, Wortgatungen, Wortkategorien - besedna plemena, vrste besed

Wort $>$ Wortbildungslehre - nauk o tvorjenji besed, besedotvorje

Wort $>$ Wortfolge - besedosledje, besedni red

Zahl $>$ Zahlwort - številnik

(b) Ob iztočnici ali podiztočnici sta navedena domači in prevzeti ustreznik:

Analogia - nalika, analogija (podčrtal S. A.), analog, nalično

Comparation $>$ Comperativ - drugi stopenj, komperativ

Participium - participij, deležnik

Partikel - nepregibnica, partikula

Substantiv - samostavnik, substantiv

Sintax - skladnja, sintaksa

Unbestimmt $>$ Unbestimmte Art - nedoločnik, infinitiv

(c) Ob iztočnici ali podiztočnici je naveden le prevzeti ustreznik:

Alliteration - aliteracija

Consonantismus - konsonantizem

Gerundium - gerundij

Localis, Locativus ${ }^{17}$ (casus) - lokal

Prosodie - prozodija

Synecdoche - sinekdoha

Gradivo kaže, da je največja prva skupina iztočnic in podiztočnic (a), ki ima le domače ustreznike, kar je pričakovano, saj je delo nastalo v drugi polovici 19. stoletja, ko je bila slovenska jezikoslovna terminologija v veliki meri že oblikovana.

15 Beseda sklanjatev je edini slovenski ustreznik med jezikoslovno označenimi termini, ki ima naveden tudi vir. Pričakovali bi, da bo vir naveden pogosteje, saj v Tolmaču nekih kratic navaja oznaki za dva jezikoslovca, in sicer Šol. za Janeza Šolarja (1827-1882) in Mikl. za Franca Miklošiča (1813-1891).

16 Cigale je v slovarju podiztočnice navajal za podpičji. V pričujočem prispevku smo zaradi večje preglednosti pred vse podiztočnice zapisali znak >: beseda, ki sledi temu znaku, je v slovarju navedena kot podiztočnica pri besedi, ki je navedena pred znakom $>$.

17 Iztočnica Localis je v slovarju navedena v latinici (latinični antikvi), medtem ko je prevladujoči črkopis iztočnic in podiztočnic gotica (fraktura), npr. $\mathfrak{B e i f p i e l . ~ Z a n i m i v o ~ j e , ~ d a ~ j e ~ C i g a l e ~ n e k a t e - ~}$ re iz klasičnih jezikov prevzete termine zapisal v gotici, npr. Analogia, Casus, Copula, druge pa $\mathrm{v}$ latinici, čeprav gre v obeh primerih za citatne termine. V slovarju so v latinični antikvi zapisani še naslednji jezikoslovno označeni termini: Caesura, Durativa verba, Hybrida vox, Localis, positivus gradus (v geslu Positio), Procliticae, Reflexivum (v geslu Reflectiren), Soloecismus, Synaloephe, Synecdoche, Systole, Transitivum verbum. 
Nekoliko manjša je druga skupina iztočnic in podiztočnic (b), ki ima ob domačih ustreznikih še tuje, pri čemer je videti, da avtor ne daje prednosti ne enemu ne drugemu ustrezniku. Tudi na osnovi razvrščanja ustreznikov ne moremo sklepati na prednost ene ali druge poimenovalne možnosti, saj je včasih na prvem mestu prevzeti ustreznik in domači ustreznik na drugem, včasih pa je vrstni red obrnjen.

Najmanjša je tretja skupina iztočnic in podiztočnic (c), za katere avtor navaja le prevzete ustreznike. V tej skupini gre torej za termine, za katere avtor meni, da je ustrezen prevzeti ustreznik, in torej niti ne skuša oblikovati domačega ustreznika oz. uveljaviti prevzetega iz kakšnega drugega slovanskega jezika.

Domnevamo, da je bila večina ustreznikov iz vseh treh obravnavanih podskupin izpričana že v starejših jezikoslovnih delih, tako da jih je Cigale le zapisal. To velja tako za domače ustreznike (npr. besedna plemena, $\mathbf{1 8}$ deležnik, 19 nedoločnik,20 oblikoslovje,21 padež,22 pridevnik,23 samostavnik,24 skladnja,25 stopnjevanje,26 številnik, $\mathbf{2 7}$ veznik, $\mathbf{2 8}$ zaimek ${ }^{29}$ ) kot tudi prevzete (npr. infinitiv, ${ }^{\mathbf{3 0}}$ sintaksa, $\mathbf{3 1}$ substantiv32). V nekaj primerih (npr. besedotvorje, besedosledje, nalika, nepregibnica, zaimenica) pa verjetno lahko tvorbo oz. vsaj prvo omembo termina $\mathrm{v}$ kakšnem jezikovnem priročniku pripišemo 33 Cigaletu.

\subsubsection{Iztočnice in podiztočnice, ki imajo poleg neoznačenega ustreznika vsaj še} enega, ki je glede na izvor označen

$\mathrm{V}$ pričujoči skupini so zbrane iztočnice in podiztočnice, označene z gr., ki imajo vsaj en glede na izvor najmanj en neoznačeni ustreznik in še najmanj enega, ki je glede na izvor označen. Poleg ustreznikov, ki jih je Cigale označil kot češke, hrva-

18 Po Pacek 2003: 48 je termin besedno pleme zapisan že v Vodnikovi slovnici (1811).

19 Termin deležnik je izpričan npr. v Janežič 1864: 247.

20 Termin nedoločnik je izpričan npr. v Janežič 1864: 248.

21 Termin oblikoslovje smo našli izpričan v Janežič 1864: 248.

22 Po Rotar 1958: 39 je termin padež izpričan že v Japljevem rokopisu Slovenische Sprache iz leta 1807.

23 Po Trojar 2017: 171 je termin pridevnik zapisan v Levstikovi slovnici (1866).

24 Po Pacek 2003: 48 je termin samostavnik zapisan že v Janežičevi slovnici (1863).

25 Termin skladnja je izpričan v Janežič 1864: 249.

26 Termin stopnjevanje je izpričan v Janežič 1854: 29.

27 Po Trojar 2017: 291 je termin številnik zapisan v Levstikovi slovnici (1866).

28 Po Trojar 2017: 172 je termin veznik zapisan v Majarjevi slovnici (1850).

29 Termin zaimek je izpričan npr. v Janežič 1864: 250.

30 Termin infinitiv je izpričan npr. v Janežič 1864: 69.

31 Termin sintaksa je izpričan npr. v Janežič 1864: 6.

32 Termin substantiv je izpričan npr. v Janežič 1864: 31.

33 Opozoriti je treba, da je prva omemba terminov pripisana Cigaletu na osnovi primerjave stanja z Janežičevo slovnico (Janežič 1864) in z jezikovnozgodovinskimi raziskavami jezikoslovne terminologije; prim. Rotar 1958; Pacek 2003; Trojar 2017. Za bolj dokončne ugotovitve bi bilo seveda treba v primerjavo vključiti še ostele slovnice slovenskega jezika iz 18 . in 19. stoletja. 
ške in starocerkvenoslovanske, v tej skupini najdemo še ustreznike, ki so označeni kot ruski, srbski in splošno slovanski.

(a) Ustrezniki, označeni kot češki:

Positio > Position - položje; stanje, nach dem Böhm. pologa

Synonymia $>$ synonymisch - istoznačni, jednoznačni, böhm. soznačni

Suffix - končnica, kroat. T. dometek, böhm. T. pritvorek

(b) Ustreznik, označen kot češki in hrvaški:

Satz > Satzband, (copula) - vez -i; (böhm. u. kroat. T.) spona

(c) Ustrezniki, označeni kot hrvaški:

Abhangen - viseti o čem (kroat. T.), stati na čem, nach dem Russ. zaviseti (als verb. impf.) od česa

Abkürzung - kratica, skratica (kroat. T.)

Bezeichnen - oznameniti, oznamenovati, nach dem Kroat. auch obeležiti, beležiti

Gedanke $>$ Gedankenstrich - pomišljaj, kroat. T. stanka

Indicativ - znanilni naklon, znanilnik (pokazni način kroat. T.)

Prädicament $>$ Prädicat - predikat, povedek, nach der kroat. T. prirok

Präfix - prednica, kroat. T. nametek

Satz $>$ Satzfolge - red ali sledba (kroat. T.) rekov

Stamm - deblo (nach der kroat. T. osnova)

Suffix - končnica, kroat. T. dometek, böhm. T. pritvorek

Verkleinern $>$ Verkleinerungswort - manjšalna, manječa (kroat. T.) beseda

(ॅ) Ustrezniki, označeni kot ruski:

Abhangen - viseti o čem (kroat. T.) stati na čem, nach dem Russ. zaviseti (als verb. impf.) od česa

Aspiration - nadih, pridih (russ.)

Hiatus - zev, russ. aakanje

(d) Ustreznik, označen kot slovanski:

Bedeuten - pomeniti (als. v. imperf., geb. aus pomen), bei anderen Slaven značiti

(e) Ustrezniki, označeni kot srbski:

Negation $>$ negiren - zanikati, nikati (Vuk $\mathbf{3 4}$ nijekati)

Satz (enunciatio, propositio) - rek, stavek (die Serben schreiben meist: rečenica analog dem wirklich gebräuchlichen činjenica Thatsache)

(f) Ustrezniki, označeni kot starocerkvenoslovanski:

Buchstab nach dem Altslav. - pisme (-ena), črka

Ironie - ironija, (tenki) podsmeh ali zasmeh; [...] nach dem Altsl. podhiba

34 Cigale (1880: X) v uvodu omenja Vukov »Rječnik«, za katerega Irena Orel (2005: 363) navaja, da je bil eden izmed Cigaletovih virov za prevzemanje. Natančnejših bibliografskih podatkov o Vukovem slovarju Cigale ne navaja. Skoraj gotovo gre za slovar Vuka Stefanovića Karadžića (1787-1864) Srpski rječnik istolkovan njemačkim i latinskim riječma iz leta 1818 ali za njegovo drugo, dopolnjeno in predelano izdajo iz leta 1852. 
Med iztočnicami in podiztočnicami s področja jezikoslovja, ki imajo vsaj en glede na izvor neoznačeni ustreznik in še najmanj enega, ki je glede na izvor označen, je največ takšnih, ki imajo ustreznike označene kot hrvaške, medtem ko za ostale jezike najdemo le po nekaj posameznih primerov.

Ob pregledu pričujoče skupine terminov bi lahko pomislili, da je avtor ob slovenskih ustreznikih dodajal tujejezične, a je to malo verjetno, ker so besede zapisane podomačeno 35 in jih torej ne moremo razumeti kot tujejezične ustreznike. Če pa obravnavane primere razumemo kot prevzete termine v slovenščino, se zastavi vprašanje, zakaj je pri posameznih iztočnicah in podiztočnicah navedeno tolikšno število ustreznikov, saj Cigale (1880: V) v uvodu med razlogi za nastanek novega slovarja med drugim navaja, da je bil njegov nemško-slovenski slovar iz leta 1860 »prepoln jednoznačnic ali soznačnic (sinonimov)«. Torej bi lahko razumeli, da se je Cigale nizanju sinonimov načeloma izogibal. Tako se kot naslednja možna razlaga takšnega stanja ponuja hipoteza, da se morda neoznačeni ustrezniki avtorju iz takšnega ali drugačnega razloga niso zdeli povsem ustrezni in je zato kot predloge dodal prevzete termine iz drugih slovanskih jezikov. A tudi takšna razlaga se ne zdi prav verjetna, saj so npr. v slovarju v geslu Prädicat navedeni ustrezniki predikat, povedek in prirok, medtem ko Cigale (1880: VIII) v uvodu o tem terminu pravi: »Tako bi tudi pri slovnici bilo bolje ostati pri izrazih: subjekt, predikat, nego zamenjati jih z neprimernimi slovenskimi.« V tem primeru torej Cigale povsem jasno daje prednost mednarodnemu (neslovanskemu) terminu. Dodaten argument, ki govori v prid temu, da iz slovanskih jezikov prevzeti ustrezniki niso bili mišljeni kot predlogi za manj ustrezne termine, je v tem, da avtor tudi sicer v uvodu uporablja glede na izvor neoznačene jezikoslovne termine namesto terminov, ki so prevzeti iz drugih slovanskih jezikov. Tako v uvodu uporabi termin končnica (Cigale 1880: XI) in ne morda dometek ali pritvorek, kot bi pričakovali, če bi iz drugih slovanskih jezikov prevzete ustreznike razumeli kot predloge za prednostne termine.

Martina Orožen (2003: 267) v zvezi s tovrstnim navajanjem prevzetih ustreznikov pravi, da »jih niza le kot izborne sinonimične možnosti za slovenski knjižni termin«, Irena Orel (2007: 359) pa, da imajo tovrstni ustrezniki »lahko samo ponazarjalno vlogo ali pa so navedeni kot predlog rabe«. Analiza jezikoslovne terminologije je pokazala, da je Cigale ob bolj ali manj ustaljenih domačih ali mednarodnih ustreznikih navajal iz slovanskih jezikov prevzete ustreznike bolj v smislu predstavitve dodatne možnosti, ki se v okviru prevzemanja ponuja tudi za poimenovanje pojmov. Pri tem pa se ni opredelil, katera možnost se mu zdi boljša, temveč je to prepustil uporabnikom slovarja. To Cigale (1880: IX) nakaže tudi v uvodu v slovar, kjer pravi:

35 Šafárik (1853) npr. v geslu synonymisch navaja češki ustreznik souznačný, ki ga je Cigale zapisal v podomačeni obliki soznačni. Podobno npr. Šulek 1874 v geslu Suffixum, Suffix navaja hrvaški ustreznik dometak, ki ga Cigale piše v podomačeni obliki dometek. 
Ali bojim se, da se bode mnogokateremu [...] zdelo, da je preveč sinonimov, premalo potankosti in določenosti. Kjerkoli utegne res takó biti ter se stvar prepušča bodočnosti [...]

Pri deležu ustreznikov iz pričujoče skupine, ki jih je oblikoval oz. prevzel Cigale, lahko ugotovimo, da je bila večina glede na izvor neoznačenih ustreznikov izpričanih že v starejših jezikoslovnih delih (npr. končnica, 36 kratica, ${ }^{37}$ pomišljaj, 38 povedek, ${ }^{39}$ prednica, ${ }^{\mathbf{4 0}}$ stavek, ${ }^{\mathbf{4 1}}$ znanilni naklon ${ }^{\mathbf{4 2}}$ ), medtem ko lahko večino glede na izvor označenih ustreznikov pripišemo ${ }^{43}$ Cigaletu (npr. dometek, nametek, pritvorek, skratica, stanka, prirok), pri čemer pa je zanimivo, da se večina teh v stroki ni uveljavila. V tem pogledu sta izjemi le termina osnova in pridih, ki sta ohranjena tudi v sodobni jezikoslovni terminologiji.44

\subsubsection{Iztočnice in podiztočnice s samo takšnimi ustrezniki, ki so glede na izvor označeni}

V pričujoči skupini so zbrane tiste iztočnice in podiztočnice, označene z $g r$., ob katerih so navedeni le ustrezniki, ki so označeni kot prevzeti. Poleg ustreznikov, ki so označeni kot češki, hrvaški in starocerkvenoslovanski, v tej skupini najdemo še rusko in hrvaško/srbsko označene ustreznike.

(a) Ustreznik, označen kot češki in hrvaški:

Lautiren - glaskovati (böhm. u. kroat. T.)

(b) Ustrezniki, označeni kot hrvaški: 45

Bilden > Bildungsendung, -laut, -suffix - tvorka (kroat. T.)

Idiom - razrečje (kroat. T.)

Pause - stanka (kroat. T.); im Reden, premolk

Rücken $>$ Rückverwandlung der Laute - vzvratna premena glasov (kroat. T.)

Verkleinern $>$ Verkleinerung - omaljek (kroat. T.)

Verlängerung eines Wortes (paragoge) - prikrpek (kroat. T.)

Wechsel $>$ Wechsellaut - glasek zamenik (kroat. T.)

Wurzel > wurzelhafter Consonant - korenit soglasnik (kroat. T.)

36 Po Rotar 1958: 41 je termin končnica zapisan že v Janežičevi slovnici (1854).

37 Termin kratica smo našli v Janežič 1854: 10.

38 Po Rotar 1958: 50 je termin pomišljaj izpričan v Janežičevi slovnici (1854).

39 Po Pacek 2003: 40 je termin povedek zapisan že v Malavašičevi slovnici (1849).

40 Termin prednica, ki ga je kasneje zamenjal termin predpona, smo našli v Janežič 1864: 152.

41 Po Rotar 1958: 39 je termin stavek izpričan v Vodnikovi slovnici (1811).

42 Po Trojar (2017: 270) je termin znanilni naklon, ki je zapisan kot znanivni naklon, izpričan v Janežičevi slovnici 1854 .

43 Gl. op. 33.

44 Tudi za termin akanje, ki ga je Cigale zapisal kot aakanje, bi lahko sklepali, da se je ohranil v sodobni jezikoslovni terminologiji, a gre v bistvu za homonim. Cigale ga navaja pri iztočnici hiatus kot sinonim za termin zev, medtem ko v sodobni jezikoslovni terminologiji označuje drug pojem, in sicer 'izgovarjanje glasu a namesto o' (SSKJ).

$45 \mathrm{~V}$ to skupino bi spadal tudi termin Vorberge, ki ima označevalnik $g r$. in ustreznik prigorje (kroat. T.); na tem mestu gre za napako: termin je s področja geografije, ki je v slovarju označena $\mathrm{z}$ označevalnikom $g g r$. 
(c) Ustreznika, označena kot ruska:

Mund $>$ Mundart - narečje (russ. etc.)

Vorwort - predlog (russ.)

(̌) Ustreznik, označen kot ruski in hrvaški/srbski:

Beispiel - primer (russ. kroatoserb.)

(d) Ustreznik, označen kot starocerkvenoslovanski in ruski:

Silbe (Syllaba) - nach dem Altsl. u. Russ. zlog

Med iztočnicami in podiztočnicami s področja jezikoslovja, ki imajo le glede na izvor označene ustreznike, je največja skupina tistih, ki jim Cigale pripisuje iz hrvaščine prevzete ustreznike. Iz ostalih jezikov prevzete ustreznike najdemo le v posameznih primerih.

Irena Orel (2007: 358) v zvezi z navajanjem samo slovanskih ustreznic ugotavlja, da jih navaja, »če domačega izraza še ni«. Tudi na področju jezikoslovne terminologije se kaže, da je v večini primerov avtor verjetno naletel na poimenovalno vrzel, ki jo je skušal zapolniti s prevzemanjem iz drugih slovanskih jezikov. Poleg skupine ustreznikov, ki jih tako verjetno lahko pripišemo 46 Cigaletu (npr. omaljek, prikrpek, stanka, tvorka), pa smo našli tudi nekaj ustreznikov (npr. narečje, ${ }^{47}$ predlog, ${ }^{48}$ razrečje, ${ }^{49}$ zlog 50 ), ki so bili izpričani že v starejših jezikoslovnih delih in za katere lahko sklepamo, da jih je Cigale le popisal in jim dodal podatek o izvoru.

\section{PREgLED CELOVITOSTI OBRAVNAVE SEDMIH POJMOVNIH SKUPIN S PODROČJA JEZIKOSLOVJA}

2.1 Naslednje raziskovalno vprašanje, ki smo si ga zastavili, je bilo, kako celovito je avtor slovarja predstavil posamezne pojmovne skupine, ki jih Borislava Košmrlj - Levačič (2009: 165) imenuje tudi tematske skupine in jih opredeli kot »celote pojmov, ki jih zajema krovna nadpomenka«.51 Analizo smo zamejili na

46 Gl. op. 33.

47 Po Pacek 2003: 48 je termin narečje izpričan že v Vodnikovi slovnici (1881), kjer označuje pojem, ki ga v sodobni jezikoslovni terminologiji označuje termin prislov. Pozneje pa termin narečje označuje pojem s področja dialektologije, kakor ga navaja tudi Cigale. V tej vlogi najdemo termin narečje izpričan npr. v pismu Matija Majerja, ki je bilo objavljeno v Kmetijskih in rokodelskih novicah (1844, št. 1, 12; vir: IMP: 〈http://nl.ijs.si/imp/nuk/dl/NUKP14041-1844. html\#pb.008) in kjer piše: »Jaz Vam pišem iz Koroškega - pa vendar pravim, da je treba s časama le bolj in bolj približovati se narečju (Dialekt), ktero se okoli Reke govori - Tisto narečje zastopimo blizo vsi južni Slavjani.«

48 Po Rotar 1958: 39 je termin predlog izpričan že v Vodnikovi slovnici (1811).

49 Termin razrečje je izpričan v Janežič 1864: 249.

50 Po Trojar 2017: 247 je termin zlog izpričan v Malavašičevi slovnici (1849).

51 Pojmovna skupina je opredeljena v okviru pojmovnega pristopa, ki se je uveljavil v sodobni terminologiji in v središče postavlja pojem kot osnovni gradnik pojmovnega sistema stroke (prim. Fajfar - Žagar Karer 2015). Ker pa pojmi navadno niso medsebojno izolirane enote, temveč se 
sedem pojmovnih skupin s področja jezikoslovja, za katere smo v slovarju našli izpričane termine, in sicer besedne vrste, jezikoslovna področja, ločila, pridevniške stopnje, slovnična števila, sklone in stavčne člene. Cilj je torej bil ugotoviti, koliko in katere termine iz omenjenih sedmih pojmovnih skupin je avtor vključil $\mathrm{v}$ slovar in katere je morda izpustil. V tem primeru v analizo nismo vključili le terminov, ki so označeni z označevalnikom $g r$, temveč smo pregledali celoten slovar. Kot referenčno delo za primerjavo smo uporabili slovnico Antona Janežiča Slovenska slovnica za domačo in šolsko rabo, ki v smislu jezikoslovne terminologije velja za najbolj izpiljeno delo tega obdobja (prim. Ahačič 2015a; Rotar 1958: 41). Pri analizi smo uporabili tretjo izdajo omenjene slovnice iz leta 1864, ki ima na koncu tudi Imenik slovniških izrazov, kar nam je pomagalo pri pregledu zajete terminologije.

(a) Termini iz pojmovne skupine besedne vrste:

Beiwort - pridevnik

Conjunction - veznik

Fürwort - zaimenica, zaimek, priimek

Nebenabsicht $>$ Nebenwort, (adverbium) - prislov

Substantiv - samostavnik,, $\mathbf{5 2}$ substantiv

Vorwort - predlog

Zahl $>$ Zahlwort - številnik

Zeit $>$ Zeitwort - glagol

Pojmovna skupina besedne vrste je v slovarju predstavljena celovito, saj Anton Janežič $(1864: 113,248)$ poleg naštetih besednih vrst navaja le še medmet, ki pa ga tudi Cigale ni prezrl, saj lahko pod iztočnico Empfinden najdemo podiztočnico Empfindungswort $\mathbf{5 3} \mathrm{s}$ kazalko na termin Interjection, ki pa v slovarju manjka.

(b) Termini iz pojmovne skupine jezikoslovna področja:

Ethymologie - etimologija, (izvajanja ali izsledovanje besed)

Form $>$ Formenlehre - oblikoslovje

Laut $>$ Lautlehre - glasoslovje, nauk o glasih

Sintax - skladnja, sintaksa

Wort $>$ Wortbildungslehre - nauk o tvorjenji besed, besedotvorje

Pojmovna skupina jezikoslovna področja je v slovarju predstavljena celovito. Podobno kot Cigale tudi Janežič (1864: 6) navaja termine za pet pojmov, in sicer

povezujejo, lahko na vmesni stopnji govorimo o pojmovnih skupinah, ki imajo pomembno vlogo tudi v sodobnem terminografskem postopku. Terminografom namreč prav organizacija dela po pojmovnih skupinah omogoča enotno oblikovanje definicij za sorodne pojme in po drugi strani zagotavlja lažji nadzor nad celovitostjo obravnave pojmovnega sistema stroke, kar je za terminološki slovar ključnega pomena.

52 Ustreznik samostavnik Cigale navaja tudi pri terminu Hauptwort, ki je podiztočnica v geslu Haupt.

53 Samostalnik Empfindungswort v nemščini označuje 'medmet'. Tudi Anton Janežič (1864: 248) v slovarčku na koncu slovnice ob terminu medmet navaja nemški ustreznik Empfindungswort. 
besedoslovje (etimologija), glasoslovje, oblikoslovje, besedoskladje ali skladje $\mathbf{5 4}$ in stavkoslovje ali skladnja (sintaksa).

(c) Termini iz pojmovne skupine ločila:

Ausrufungszeichen - klicaj

Beistrich - vejica

Bindegewebe $>$ Bindungszeichen - vezaj

Doppel $>$ Doppelpunct - dvopičje

Frage $>$ Fragezeichen - vprašaj

Gedanke $>$ Gedankenstrich - pomišljaj, kroat. T. stanka

Klammer - oklepaj, zaporka (prednja, zadnja)

Schließen $>$ Schlußpunct - pika

Strich $>$ Strichpunct - podpičje

Vsaj jedrni del pojmovne skupine ločila je v slovarju predstavljen celovito. Janežič (1864: 248) poleg terminov za naštetih devet pojmov navaja le še termina narekovaj

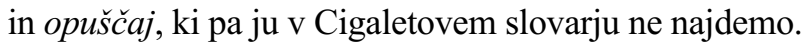

(こ̌) Termini iz pojmovne skupine pridevniške stopnje:

Comparation $>$ Comperativ - drugi stopenj, komperativ

Positio $>$ positivus gradus - prvi stopenj, (prva stopinja), pozitiv

Kljub temu da bi pričakovali tri pridevniške stopnje, v slovarju najdemo navedeni le dve. V primerjavi s Cigaletom Janežič (1864: 50) navaja vse tri pridevniške stopnje, in sicer perva ali nasebna (positiv), druga ali sodnja (komparativ) in tretja ali presežna stopnja (superlativ).

(d) Termini iz pojmovne skupine slovnična števila:

Dual - dvojina

Einzahl - ednina

Mehr > Mehrzahl - množina

Pojmovna skupina slovnična števila je v slovarju predstavljena celovito. Tudi Janežič (1864: 33) navaja termine za tri števila, in sicer edinje ali ednina (singular, Einzahl), dvojno ali dvojina (dual, Zweizahl) in množno ali množina (plural, Mehrzahl).

(e) Termini iz pojmovne skupine skloni:

Localis, Locativus, (casus) - lokal

Nomen $>$ Nominativ - prvi padež, imenovalnik

54 Janežič (1864: 6) besedoskladje ali skladje opredeljuje kot področje, ki proučuje »kako se besede skladajo t. j. obrazilijo ali sestavljajo«. Torej označuje isti pojem, kot ga pri Cigaletu označujeta termina nauk o tvorjenji besed in besedotvorje. 
Pojmovna skupina skloni je v slovarju predstavljena pomanjkljivo, saj v slovarju presenetljivo najdemo le dva termina, medtem ko bi jih pričakovali (vsaj) šest. Janežič (1864: 166-176) v svoji slovnici navaja sedem sklonov, in sicer imenovavnik (nominativ), rodivnik (genitiv), dajavnik (dativ), toživnik ali kazavnik (akkusativ), zvavnik (vokativ), mestnik (lokal) in druživnik ali orodnik (instrumental).

(f) Termini iz pojmovne skupine stavčni členi:

Attribut - pridevek, atribut

Object, Objectum - objekt

Prädicament $>$ Prädicat - predikat, povedek, nach der kroat. T. prirok

Subject - podmet (böhm. u. kroat. T.), auch russ. subjekt

Če predpostavimo, da je avtor tudi pri terminu Object, kljub temu da ga je označil z označevalnikom phil., imel v mislih (tudi) pojem s področja jezikoslovja, lahko ugotovimo, da je pojmovna skupina stavčni členi predstavljena precej celovito.55 Janežič (1864: 155-156), ki za obravnavane štiri pojme sicer navaja drugačne termine, 56 poleg tega navaja le še termin prirečje ali prislovni (adverbialni) določek. 57

2.2 Analiza sedmih pojmovnih skupin s področja jezikoslovja je pokazala, da je Cigale pojmovni skupini jezikoslovna področja in slovnična števila predstavil celovito. Pri pojmovnih skupinah besedne vrste, ločila in stavčni členi smo opazili manjše pomanjkljivosti, ki jih lahko vsaj v primeru pojmovne skupine besedne vrste pripišemo terminografski napaki, v primeru pojmovnih skupin ločila in stavčni členi pa gre za umanjkanje posameznih terminov, ki sicer ne označujejo jedrnih pojmov. Večje pomanjkljivosti se kažejo pri pojmovnih skupinah pridevniške stopnje in skloni, kjer manjkajo termini za enakovredne pojme iz pojmovne skupine.

\section{SKLEP}

V Cigaletovi Znanstveni terminologiji je večina ustreznikov ob iztočnicah in podiztočnicah s področja jezikoslovja glede na izvor neoznačenih, in sicer prevladujejo domači ustrezniki, obsežen pa je tudi delež prevzetih in v podomačeni obliki zapisanih terminov iz klasičnih jezikov. Pri nekaj več kot desetini iztočnic in podiztočnic s področja jezikoslovja je ob ustreznikih naveden podatek o izvoru, ki se v večini primerov nanaša na prevzemanje iz hrvaščine. V nekaterih posameznih primerih so bili tovrstni termini izpričani že v starejših jezikoslovnih delih, v

55 Tudi termin Subject je (podobno kot termin Object) označen le z označevalnikom phil., a v tem primeru ni dvoma, da ga je uporabljal tudi kot termin s področja jezikoslovja, saj je to eksplicitno navedel v uvodu (prim. Cigale 1880: VIII).

56 Anton Janežič (1864: 247-250) navaja termin Subjekt kot ustreznik za termin osebek, Prädikat kot ustreznik za dopovedek, Attribut kot ustreznik za prilastek in pridevek ter Objekt kot ustreznik za termina dopolnek in predmet.

57 Prirečja ali prislovne (adverbialne) določke Janežič (1864: 156) opredeljuje kot določke, »po katerih se določa kraj, čas, način ali vzrok kacega djanja«. 
večini primerov pa verjetno lahko prevzemanje pripišemo Cigaletu. Iz slovanskih jezikov prevzete termine je avtor navajal samostojno, torej $\mathrm{v}$ funkciji zapolnjevanja poimenovalne vrzeli, ali pa kot potencialno poimenovalno možnost ob že ustaljenih terminih. Menimo, da v ozadju tovrstnega nizanja potencialnih poimenovalnih možnosti ni bila menjava terminologije, temveč bolj predstavitev smeri, v katero naj bi šel razvoj slovenske terminologije v prihodnje, da bi se slovanski narodi med seboj lažje sporazumevali. Zanimivo je, da so se uveljavili le posamezni Cigaletovi prevzeti termini, medtem ko jih večina v rabi ni zaživela.

Tudi v zvezi z obravnavo pojmovnih skupin lahko rečemo, da gre v primeru Cigaletove Znanstvene terminologije za dobro premišljeno delo, pri katerem se je avtor dobro zavedal pomena celovitosti obravnave posameznih strokovnih področij, njihovih pojmovnih sistemov in znotraj njih pojmovnih skupin. Kažejo se sicer posamezne nedoslednosti, kar pa je razumljivo, saj je šlo za enoavtorski slovar s kar štiriindvajsetimi strokovnimi področji. Sklenemo lahko, da gre tako v terminološkem kot tudi terminografskem pogledu za veliko delo, in lahko se le strinjamo z Martino Orožen (2003: 267), ki v zvezi s Cigaletom in njegovim terminološkim delom pravi, da »bi vsak slovenski terminolog moral poznati in upoštevati njegovo delo«.

\section{VIRI}

Cigale 1880 = Matej Cigale, Znanstvena terminologija s posebnim ozirom na srednja učilišča, Ljubljana: Matica slovenska, 1880.

IMP = Jezikovni viri starejše slovenščine IMP $\langle\mathrm{http}: / / \mathrm{nl} . \mathrm{ijs} . \mathrm{si} / \mathrm{imp} /\rangle$.

Janežič $\mathbf{1 8 5 4}$ = Anton Janežič, Slovenska slovnica s kratkim pregledom slovenskega slovstva ter z malim cirliskim in glagoliškim berilom za Slovence, V Celovcu: E. Liegl, 1854.

Janežič $\mathbf{1 8 6 4}$ = Anton Janežič, Slovenska slovnica za domačo in šolsko rabo, V Celovcu: E. Liegl, 31864.

Šafárik 1853 = Pavel Josef Šafařík, Německo-český slovník vědeckého názvosloví pro gymnasia a reálné školy, V Praze: Kalve'ské knihkupectví, 1853.

Šulek 1874 = Bogoslav Šulek, Rječnik znanstvenoga nazivlja, osobito za srednja učilišta, Zagreb: Tiskom Narodne tiskare Dra. Ljudevita Gaja, 1874.

\section{LITERATURA}

Ahačič 2007 = Kozma Ahačič, Jezikoslovna terminologija pri slovenskih protestantskih piscih 16. stoletja, v: Besedje slovenskega jezika, ur. Marko Jesenšek, Maribor: Slavistično društvo, 2007 (Zora 50), 127-135.

Ahačič 2015a = Kozma Ahačič, Anton Janežič: Slovenska slovnica za domačo in šolsko rabo, v: Slovenske slovnice in pravopisi: spletišče slovenskih slovnic in pravopisov od 1584 do danes: različica 1.0, ur. Kozma Ahačič 〈https://fran.si/slovnice-in-pravopisi/26/18631854-janezic〉.

Ahačič 2015b = Kozma Ahačič, Tipologija slovenskih slovnic, v: Slovnica in slovar - aktualni jezikovni opis 1, ur. Mojca Smolej, Ljubljana: Znanstvena založba Filozofske fakultete, 2015 (Obdobja 34), 15-30.

Atelšek 2005 = Simon Atelšek, Vpliv češkega izrazja iz Šafárikovega terminološkega slovarja (1853) na Cigaletovo Znanstveno terminologijo (1880): diplomsko delo, Filozofska fakulteta v Ljubljani, 2005. - Tipkopis. 
Fajfar - Žagar Karer 2015 = Tanja Fajfar - Mojca Žagar Karer, Pojmovni pristop k izdelavi terminološkega slovarja, v: Slovnica in slovar - aktualni jezikovni opis 1, ur. Mojca Smolej, Ljubljana: Znanstvena založba Filozofske fakultete, 2015 (Obdobja 34), 209-216.

Košmrlj - Levačič 2009 = Borislava Košmrlj - Levačič, Izdelava ontologij kot faza terminografskega dela ob nastajajočem Botaničnem terminološkem slovarju, v: Terminologija in sodobna terminografija, ur. Nina Ledinek - Mojca Žagar Karer - Marjeta Humar, Ljubljana: Založba ZRC, ZRC SAZU, 2009, 163-176.

Macun 1862 = Ivan Macun, Slovenska terminologija v obče in posebno jezikoslovna, Slovenski glasnik 8.2 (1862), 67-73.

Orel 2007 = Irena Orel, Prvi slovenski terminološki slovar ter hrvaški in češki vir, v: Razvoj slovenskega strokovnega jezika, ur. Irena Orel, Ljubljana: Filozofska fakulteta, Oddelek za slovenistiko, Center za slovenščino kot drugi/tuji jezik, 2007 (Obdobja 24), 343-364.

Orožen 2003 = Martina Orožen, Oblikovanje slovenskega strokovnega izrazja (ob Cigaletovem nemško-slovenskem terminološkem slovarju), v: Razvoj slovenske jezikoslovne misli, Maribor: Slavistično društvo, 2003 (Zora 26), 259-278.

Pacek 2003 = Mojca Pacek, Jezikoslovno izrazje 19. stoletja, Slavistična revija 51.1 (2003), 33-51.

Rotar 1958 = Janez Rotar, Naše jezikovno izrazje, Jezik in slovstvo 4.2+3 (1958), 37-41, 78-81.

Škofic 2006 = Jožica Škofic, Škrabec o Janezu Šolarju, v: Zbornik Škrabčeva misel 5: zbornik s simpozija 2005: jezikoslovci in njihova dela $v$ Škrabčevih očeh, ur. Jože Toporišič, Nova Gorica: Frančiškanski samostan Kostanjevica, 2006, 229-243.

Šolar 1862 = Janez Šolar, O slovnični terminologiji, Slovenski glasnik 8.6 (1862), 204-206.

Trojar 2017 = Mitja Trojar, Development of Slovenian linguistic terminology in Slovenian grammars in the $18^{\text {th }}$ and $19^{\text {th }}$ centuries: doktorska disertacija, Univerza v Novi Gorici, 2017. - Tipkopis.

\section{SUMMARY}

\section{The Use of Borrowed Linguistic Terms and Comprehensiveness of Terminology Groups in Matej Cigale's Znanstvena terminologija (1880)}

In Matej Cigale's Znanstvena terminologija (Technical Terminology, 1880), the majority of equivalents next to linguistics-related entries and subentries are unmarked in terms of origin; specifically, Slovenian equivalents predominate, but there is also a substantial share of terms borrowed from classical languages and written in a Slovenianized form. With just over a tenth of the entries and subentries from the field of linguistics, information on their origin is provided next to the equivalents and in most cases refers to borrowing from Croatian. In some individual cases, these types of terms were already attested in older linguistic works, but in most cases the borrowing can most likely be ascribed to Cigale. He listed terms borrowed from Slavic languages as independent entries-that is, in the function of filling terminology gaps or as a potential naming option alongside already established terms. The reason for such listing of potential naming options was most likely not to change the terminology, but to present the direction in which Slovenian terminology should develop in the future to facilitate communication between the Slavic nations. It is interesting that only individual terms borrowed by Cigale have become established in practice, whereas the majority have never been really used.

With regard to the examination of terminology groups, it can be concluded that $\mathrm{Ci}$ gale's Znanstvena terminologija is a well-thought-out work, in which the author was well aware of the importance of comprehensively covering individual technical fields, their terminology systems, and the terminology groups inside them. Certain inconsistencies can be identified, but this is understandable because this was a single-author dictionary covering a full twenty-four technical fields. It can be concluded that from both the terminology and terminography perspective this was an impressive work and that Martina Orožen rightfully said, in relation to Cigale and his terminology work, that "every Slovenian terminologist should be familiar with and take account of his work." 